\title{
Les premiers Hommes en Normandie
}

\section{Dominique Cliquet}

\section{OpenEdition \\ Journals}

\section{Édition électronique}

URL : https://journals.openedition.org/adlfi/3963

ISSN : 2114-0502

Éditeur

Ministère de la Culture

Référence électronique

Dominique Cliquet, « Les premiers Hommes en Normandie » [notice archéologique], ADLFI. Archéologie de la France - Informations [En ligne], Normandie, mis en ligne le 01 mars 2009, consulté le 22 juin

2021. URL : http://journals.openedition.org/adlfi/3963

Ce document a été généré automatiquement le 22 juin 2021.

(c) ministère de la Culture et de la Communication, CNRS 


\title{
Les premiers Hommes en Normandie
}

\author{
Dominique Cliquet
}

Date de l'opération : 2009 (PC)

Comme nous l'avons évoqué dans les précédents bilans annuels et dans le bilan effectué dans le cadre de la nouvelle programmation, le projet collectif de recherche «Les premiers Hommes en Normandie " s'inscrit dans le nouveau développement de la recherche portant sur les périodes anciennes, les premiers peuplements de Normandie.

Comme les quatre années précédentes (2005 à 2008), l'année 2009 a été consacrée à l'exploitation des nombreuses données accumulées depuis les neuf années de fonctionnement du groupe de travail, à la poursuite du projet de cartographie vectorisée relative aux matières premières potentiellement utilisables par les pré- et protohistoriques et surtout à la préparation de manuscrits et d'articles de synthèse.

L'activité de terrain a été moins importante que l'an passé. Nous avons cependant procédé à la conduite de deux opérations de fouilles - avec l'achèvement des investigations sur le gisement de Saint-Pierre-Eglise, dans la Manche, et l'ouverture d'une grande fenêtre sur le site paléolithique supérieur de Rouvres - Ouilly-le-Tesson dans le Calvados - avec la réalisation de sondages d'évaluation à Feuguerolles-Bully (Calvados) et surtout sur l'important site d'ateliers de Saint-Brice-sous-Rânes (Orne).

Parallèlement à ces activités et maintenant depuis neuf années, les prospections se sont poursuivies sur certains espaces géographiques mal documentés (centre Manche, sud Manche, sud Orne, Bessin, Lieuvin, etc.).

Qu'en-est-il de la recherche quaternaire en Basse-Normandie ?

Comme nous l'avons évoqué dans les précédents bilans, les divers travaux conduits dans le cadre du PCR ont permis la révision de la documentation ancienne, la reprise des collections, voire la réouverture de sites anciennement fouillés, ce dans l'optique de proposer un bilan quantitatif et qualitatif des données enregistrées à la carte 
archéologique du Service régional de l'archéologie pour le Paléolithique et le Mésolithique.

Ce bilan synthétique, qui a été proposé dans le rapport 2005, a été complété afin de livrer les derniers acquis principaux et d'analyser leur intégration à la nouvelle programmation (continuité, définition de nouveaux axes de recherches, nouvelles méthodologies).

Rappelons que les résultats novateurs des premières investigations conduites dans le cadre du projet collectif avaient permis l'organisation de l'excursion de l'Association française pour l'étude du Quaternaire (mai 2006), travail dont l'aboutissement consiste en une copieuse publication dans le numéro 3 de la revue Quaternaire,consacré à la Normandie, paru en fin d'année 2009.

Par ailleurs, d'autres travaux sont en cours : la monographie consacrée aux occupations paléolithiques des sites du Long-Buisson sur les communes de Guichainville et du VieilEvreux, dont le manuscrit a été remis en août 2007, et la monographie consacrée aux occupations humaines et au site quaternaire classé, de renommée européenne, de Saint-Pierre-lès-Elbeuf (Seine-Maritime).

En somme, le bilan consacré à la recherche en Basse-Normandie, et plus particulièrement la partie consacrée à la Préhistoire ancienne, a permis de mettre en exergue les points forts et les faiblesses de cette recherche.

Parmi les points forts, figurent encore en 2009:la constitution d'un référentiel chronologique fondé sur les datations radiométriques, l'approche technologique des mobiliers lithiques, l'analyse de l'occupation de l'espace, dans les environnements ouverts (Bessin, Plaine de Caen, "Espace d'Ecouché ») et la «frange littorale » (Hague, Val de Saire), et enfin, la mise au jour de niveaux d'occupation de la fin du Paléolithique supérieur.

\section{Constitution d'un référentiel chronologique fondé sur les datations radiométriques}

La plupart des niveaux d'occupation et des formations majeures ont fait l'objet de prélèvements et sont en cours de traitement (OSL sur quartz et sur feldspath). Il reste cependant les niveaux de plage supposés du stade 9 de Barneville (Manche) et du stade 7 d'Equeurdreville (Manche) à prélever et à dater. Le site immergé de la Mondrée à Fermanville devrait aussi être l'objet de notre attention cette année.

\section{Approche technologique des mobiliers lithiques}

C'est l'ensemble de la chaîne opératoire qui est ici étudiée, depuis l'acquisition des matières premières jusqu'à l'abandon du nucléus et des produits utilisés.

Si de nombreux travaux universitaires ont été conduits dans le cadre d'études technologiques, les problèmes d'acquisition et d'accessibilité aux matières premières ont longtemps été négligés. Les analyses gitologiques et l'aptitude des matières premières à la taille n'ont été abordées que très récemment, en raison de la difficulté et de l'ampleur de la tâche. Deux travaux universitaires pionniers ont initié la prise en compte de cette thématique, fondamentale pour la compréhension des schémas opératoires de débitage et/ou de façonnage des matières premières lithiques, et pour l'appréhension de la fonction de certains sites et de la notion de territoire (Coutard, 1998 ; Lasseur, 2001). Comme nous l'avons signifié dans les bilans précédents, en ce qui concerne les études gîtologiques, la Normandie accuse un certain retard par rapport à d'autres espaces géographiques européens, tels que l'Europe moyenne, 
l'Europe orientale, et dans l'hexagone, le Quercy, le Périgord et plus récemment les vallées de la Somme et de la Vanne.

La thématique inhérente aux rapports entretenus entre l'Homme et la (ou les) matière(s) première(s) lithique(s) a, entre autres, initié un travail de cartographie vectorisée des gîtes de matières premières susceptibles d'avoir été utilisées par les préhistoriques. L'achèvement de ce travail sera prioritaire en 2010 afin de pouvoir faire évoluer l'outil. En effet, ce travail nécessite des prolongements, notamment des vérifications de terrain et la constitution d'un référentiel (lithothèque) accompagné d'une expérimentation inhérente à l'aptitude à la taille des différentes matières premières et à leur résistance à l'utilisation (usure). La mise en place de cette thématique portant sur les matières premières nécessite un investissement de la part des néolithiciens et dans une moindre mesure des protohistoriens, tant au plan des protocoles, que de l'investissement en temps et bien évidemment en moyens financiers. Rappelons que si le SIG portant sur les matières premières lithiques est utilisé par l'ensemble de la communauté scientifique, ce sont les géomorphologues et les paléolithiciens du PCR «Les premiers Hommes en Normandie » qui ont nourri la base de données initiale. Ce travail a donc nécessité, d'une part, une grande disponibilité en temps, d'autre part, la mise à disposition de moyens financiers pour effectuer le travail de cartographie à partir de la documentation analysée.

Analyse de l'occupation de l'espace, dans les environnements ouverts (Bessin, Plaine de Caen, «Espace d'Ecouché ») et la «frange littorale» (Hague, Val de Saire)

Ces observations permettent une approche palethnographique des occupations du Paléolithique normand dont la synthèse est en cours de rédaction.

\section{Paléolithique supérieur}

Comme nous l'avons souligné à maintes reprises, les bilans qualitatif et quantitatif des sites et des indices de sites rapportables au Paléolithique supérieur, recensés en BasseNormandie, évoqueraient un vaste désert humain durant cette période. En effet, hormis une série d'artefacts mêlés à du mobilier mésolithique et néolithique trouvée à l'occasion de prospections fines sur le site de Curcy-sur-Orne (Calvados, prospections J.J. Dédouit), le Paléolithique supérieur n'était représenté que par quelques rares pièces isolées, sorties de tout contexte.

Ce cruel déficit a motivé la recherche d'indices d'occupations du Paléolithique supérieur et la reprise des collections de surface conservées dans les dépôts de fouilles. Si les prospections et les travaux engagés depuis 2001 attestent de la présence discrète d'Hommes modernes à la fin de la période dans la Manche, dans le sud de l'Orne et d'occupations plus tangibles dans le Calvados, les mobiliers collectés anciennement comportent beaucoup plus fréquemment qu'on aurait pu s'y attendre des "pointes aziliennes » déterminées comme couteaux à dos néolithiques. La reprise de la totalité des collections de surface est à poursuivre afin de répertorier ces matériels et de tenter d'apprécier la conservation partielle de certains niveaux archéologiques en fonction des espaces géographiques (travail de longue haleine en cours). Ces vestiges sont datés du Tardiglaciaire (uniquement en Plaine de Caen, dans l'état actuel de la recherche). Une étude préliminaire, conduite par Miguel Biard, en 2004, atteste de témoins rapportables aux cultures aziliennes (Federmesser) et du Dryas récent. Depuis ce bilan, un petit lot de pièces éparses est venu compléter notre carte des indices de sites. 
Constitué de produits laminaires et d'outils (pointes aziliennes), cet ensemble a été collecté à Saint-Pierre-Eglise durant les fouilles conduites entre 2007 et 2009, sur le site paléolithique moyen, soit en surface, soit dans la partie sommitale destructurée du niveau d'occupation du Paléolithique moyen. Le nombre d'objets et leur nature (outils) plaident en faveur de l'existence d'un niveau d'occupation, vraisemblablement implanté à l'endroit où a été érigé le château d'eau et où ont été enterrées les citernes à eau, sur le sommet topographique du Val de Saire, le Mont Etolan.

Enfin, rappelons la mise en évidence d'une série belloisienne par C. Escolano sur Rouvres - Ouilly-le-Tesson (Calvados), site qui a fait l'objet de sondages en 2006 et d'une intervention en 2009.

Les activités de terrain font l'objet de notices plus développées dans ce bilan.

Enfin, la post-fouille du site de Tourville-la-Rivière se poursuit. En effet, l'opération conduite sur ce gisement, au printemps 2008, dans le cadre de l'archéologie préventive, avait permis la mise au jour de nombreux vestiges de faune (environ 450 objets) dont $1 / 8^{\mathrm{e}}$ avait nécessité un démontage en «coque de plâtre» en raison de leur état de conservation.

Comme nous l'avons énoncé dans le précédent bilan, les investigations ont concerné environ $3500 \mathrm{~m}^{2}$ dont le décapage a permis de mettre en évidence, à l'est de l'ouverture, un chenal occupé dans sa partie centrale par un banc sableux sur lequel se concentraient les vestiges de faune (environ 450 pièces) et les artefacts lithiques (environ 400 objets). À l'ouest de ce bras mort, une zone humide a été mise en évidence (secteur marécageux), où les vestiges s'avèrent plus dispersés.

Le matériel archéologique est issu des niveaux D1, D2, D3 et E, dans des proportions très variables. L'essentiel des vestiges provient du niveau D2.

En D1, sable fin un peu limoneux gris-jaune, les restes de faune sont d'aspect frais à émoussé, parfois groupés artificiellement par les turbulences du fleuve. Quelques poches pluridécimétriques comportent des restes osseux de petits mammifères assez bien conservés. Les rares artefacts lithiques rencontrés sont soit émoussés, soit roulés.

En D2, le matériel osseux et lithique provient de toute l'épaisseur de la couche, soit, du sable limoneux brun foncé, soit, de l'horizon ocre-rouille ferro-manganique, ou bien de la partie sommitale de l'horizon sablo-limoneux brun-jaunâtre. En règle générale, la faune apparaît bien conservée dans le sommet de la couche (sable limoneux brun foncé), alors que les os sont souvent altérés dans le sable limoneux brun-jaune et très dégradés dans le liseré ocre-rouille. Le mobilier lithique présente des aspects divers, « frais », lustré et émoussé.

Le niveau D3 n'a livré que de rares silex taillés et vestiges de faune, relativement bien conservés dans la partie nord-est du site.

Enfin, le niveau E ne comporte que quelques ossements d'aspect frais. Aucun artefact n'y a été collecté.

L'analyse archéozoologique a nécessité un important nettoyage des pièces de faune et pour les plus fragiles d'entre-elles une consolidation. Celle-ci a été faite partiellement par l'INRAP et environ 140 d'entre-elles par Anne-Lise Poder, après nettoyage des ossements par des agents du SRA de Basse-Normandie et des acteurs du PCR. L'étude archéozoologique conduite par Céline Bémili (INRAP) est actuellement en cours.

Cependant, rappelons que les diverses observations qui avaient pu être effectuées durant la fouille avaient confirmé une occupation anthropique du fond de vallée sur 
une grande surface, comme l'attestaient déjà les investigations menées par G. Carpentier (1981) et Luc Vallin (1982-1984).

Des indices d'occupations humaines sont donc attestés pour la fin de l'avant-dernier interglaciaire (D1, corrélé avec le stade 7) et une aire d'acquisition en matières carnées (chasse, collecte sur des animaux fraîchement tués) pour le début de l'avant-dernier glaciaire (D2 et D3, corrélé avec le stade 6).

L'ensemble des résultats sera présenté dans le cadre d'un rapport spécifique courant 2010 et figurera, de ce fait, dans le BSR Haute-Normandie des opérations 2010.

(Fig. $n^{\circ} 1$ : Curcy-sur-Orne (14) : armatures du Paléolithique supérieur final, collections J.-J. Dédouit )

Dominique CLIQUET pour l'ensemble des acteurs du PCR

\section{ANNEXES}

Fig. ${ }^{\circ} 1$ : Curcy-sur-Orne (14) : armatures du Paléolithique supérieur final, collections J.-J. Dédouit

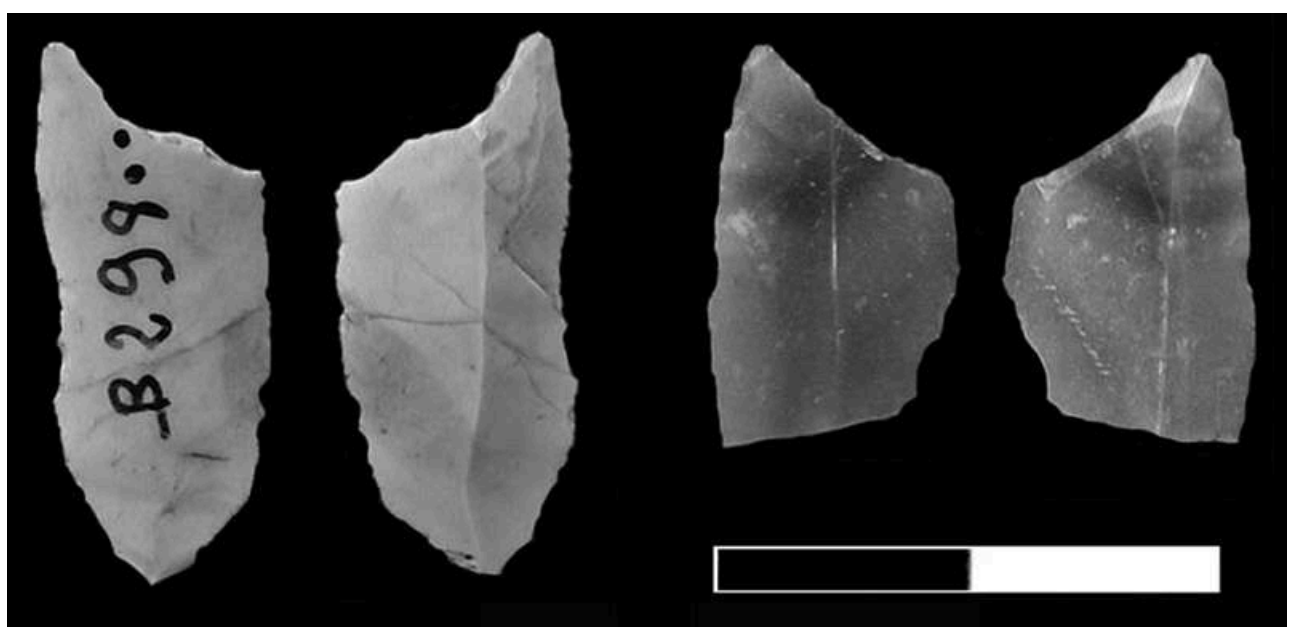

Auteur(s) : Barge, Jean. Crédits : Barge, Jean (2009)

\section{AUTEURS}

\section{DOMINIQUE CLIQUET}

SRA 